\title{
COMPOSIÇÃO QUÍMICA DE CROMITAS EM CORPOS METAMÁFICO/ULTRAMÁFICOS DA BORDA LESTE DO ESPINHAÇO MERIDIONAL, MINAS GERAIS
}

\author{
Nélson Angeli \& Sebastião Gomes de Carvalho (*)
}

\begin{abstract}
The study of variation in chemical composition of chromites associated with mafic/ultramafic sequences has a growing in importance because presents a close relation to gold and platinum group elements concentration. The researched areas : Serro, Alvorada de Minas and Morro do Pilar present chromites (massive, disseminated and accessory), which show a strong zoning due to hydrotermal/metamorphic process. These zones reflect changes in chemical composition of crystals, which are related to neoformation of mineral paragenesis based mainly on leaving of the elements in chromites ( for example the origin of kammererites).

In chromitites from Serro and Alvorada de Minas, as well as in accessory chromites from Morro do Pilar, the zoning of the grains was observed. They have a core composed by chromites (aluminous chromites) and a broad margin with ferriferous composition (chromium magnetites to magnetites). In same cases the chromite crystals have a core with primary chemical composition preserved. In the Rio Mata Cavalo volcano-sedimentary sequence a Ir-Pt alloy was found as inclusion in chromium-magnetite. In others mafic/ultramafic complex of Minas Gerais and Ceará States, high relations of PGE and Au has been recorded, and they are associated with chromitites submitted to this alteration process.
\end{abstract}

\section{INTRODUÇÃO}

A composição química das cromitas estudadas em geral é bastante variável, de tal forma que pode conter de 30 a $60 \%$ de $\mathrm{Cr}_{2} \mathrm{O}_{3}$, fato que se relaciona a duas razões básicas : natureza e composição do magma original e/ou condições superimpostas de alteração (hidrotermalismo ou metamorfismo). Este trabalho procura mostrar, pelas cromitas estudadas o segundo caso, onde fatores epigenéticos contribuíram para a mudança na composição das cromitas. Os mesmos são importantes para o entendimento dos processos deformacionais e metamórficos na evolução geológica da borda leste do Espinhaço Meridional. É também intenção, após resolvida esta questão, trabalhar no futuro com a pesquisa de PGE e Au em alvos selecionados nas seqüências pesquisadas.

Duas áreas foram escolhidas para esta pesquisa preliminar, onde se procurou regiões que contivessem valores anômalos em PGE e Au. Assim centralizou-se os estudos nas regiões do Serro (a norte) e de Morro Pilar (a sul), conforme Figura 1. Ambas apresentam aluviões platiníferas, como também mineralizações em planitóides associadas a preenchimento de fraturas e microfalhas nos quartzitos regionais. Em vários complexos máfico-ultramáficos estudados, tanto no exterior quanto no Brasil, as mineralizações em metais nobres se associam a eventos hidrotermais, que por sua vez se relacionam intimamente com a variação composicional dos cristais de cromita (Talkington et al. 1984; Gauthier et al. 1990; Thalhammer et al. 1990; Tarkian et al. 1991; Angeli 1993 e Angeli et al. 1993).
Estes cristais geralmente apresentam-se zonados, e quando não, exibem isomorfismo, neste caso com variações composicionais onde o $\mathrm{Cr}_{2} \mathrm{O}_{3}$ ou o $\mathrm{Al}_{2} \mathrm{O}_{3}$ são substituídos por $\mathrm{FeO}$ ou $\mathrm{MgO}$. Mais frequentemente ocorre uma mistura isomórfica de vários termos, mas é possível detectar-se cristais com núcleo mais cromífero e bordas com composição mais ferrífera. Vários trabalhos publicados evidenciam a ação do metamorfismo sobre as cromitas, entre os quais se destacam : Bliss \& MacLean (1975); Evans \& Frost (1975); Alapieti et al. (1989) e Kimball (1990). Nestas publicações pode-se observar que existe uma migração de elementos químicos devida ao metamorfismo, a qual se reflete no zoneamento dos cristais de cromita.

\section{GEOLOGIA DO ESPINHAÇO MERIDIONAL}

Seis grandes unidades litoestratigráficas compõem o arcabouço geológico regional do Espinhaço Meridional : Complexo Basal, Seqüência VulcanoSedimentar do Serro e do Rio Mata Cavalo, Supergrupo Rio Paraúna, Seqüência Itabirítica, Supergrupo Espinhaço e Supergrupo São Francisco (Assis 1982; Uhlein 1982; Assis \& Marini 1983 e Fogaça 1985). A seqüência Serro (Ulhein \& Dardenne 1984) apresenta um conjunto de rochas ultramáficas metamorfisadas (baixo grau - fácies dos xistos verdes), as quais apresentam intercalações de metassedimentos químicos e detríticos. Segundo estes autores a idade da sequiência deve ser arqueana e a mesma deve fazer parte de um greenstone belt. Para Renger (1972) esta sequiência corresponde a um ambiente de fácies eugeossinclinal, 


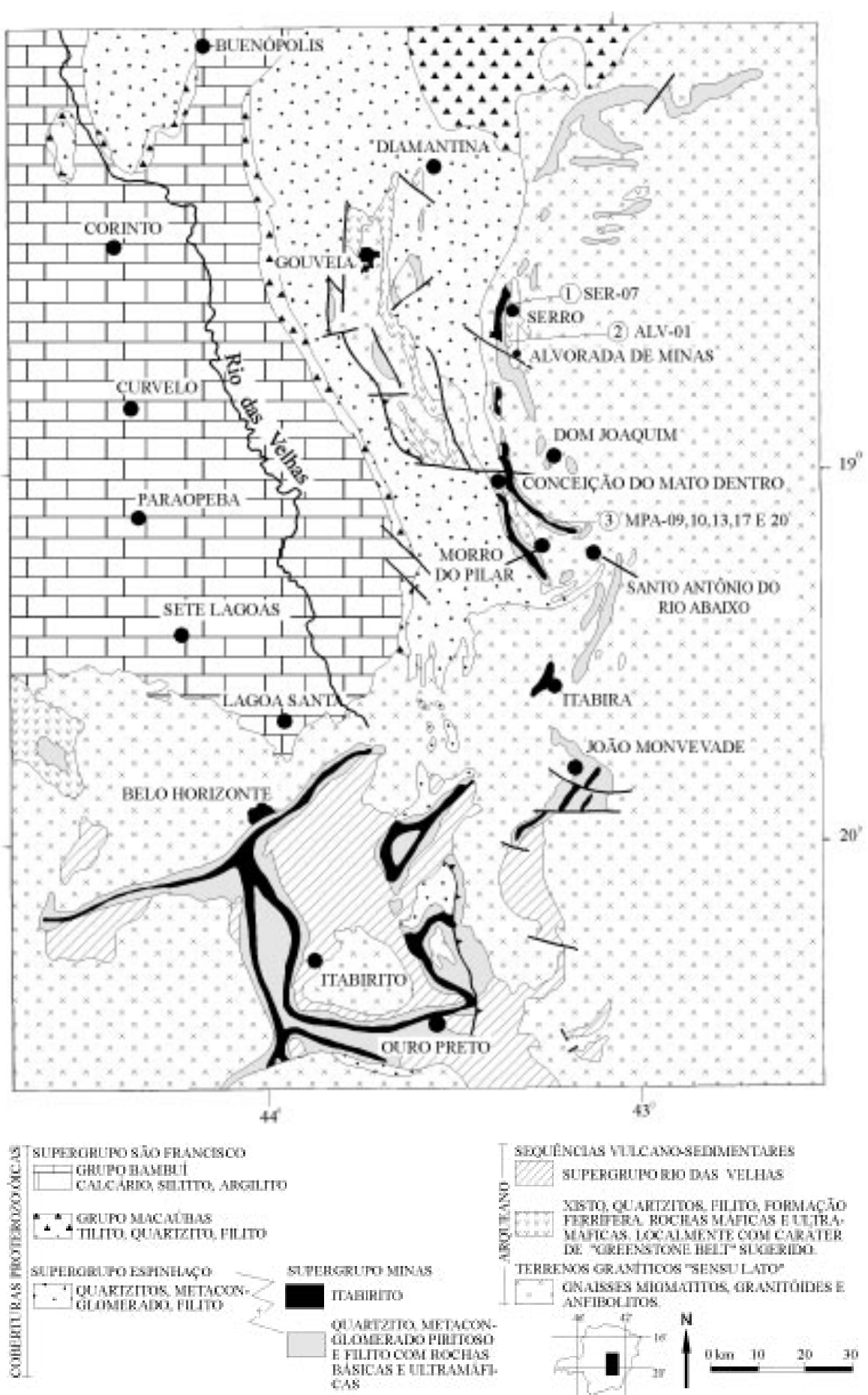

Figura 1: Mapa geológico regional com localização das áreas pesquisadas (1 - Serro, 2 - Alvorada de Minas e 3 - Morro do Pilar) e das amostras analisadas. Figura extraída de Borba et al. (1987).

Figure 1: Regional Geological Map with localization of researched areas (1 - Serro, 2 - Alvorada de Minas and 3 - Morro do Pilar) and Analysed Samples (from Borba et al. 1987).

o qual se estende desde Rio Vermelho (a norte) chegando até Morro do Pilar (a sul). Desta forma este autor caracteriza esta faixa como um cinturão tipo alpino, o qual foi submetido à vários estágios de alterações (serpentinização, cloritização e anfibolitização, esteatitização e carbonatização).

Esta sequiência foi submetida a cavalgamentos de E para $\mathrm{W}$ e se encontra em contato com rochas do embasamento cristalino (Complexo Basal) a leste e com metassedimentos de natureza quartzítica (Seqüência Jacém - Super Grupo Espinhaço) a oeste (Abreu et al. 1989 e Knauer 1990). Mais especificamente, na borda leste da Serra do Espinhaço, ocorrem pequenos corpos lenticulares, alongados, alinhados e com composição máfica-ultramáfica, os quais se encontram associados à Sequência Vulcano-Sedimentar do Serro. Aqui também são incluídos os corpos de Alvorada de Minas. Esta sequência apresenta uma série de ocorrências de 
cromititos (Renger 1972; Uhlein 1982 e Assis 1982). A feição estrutural mais importante desta sequência em relação às demais é o tipo de contacto, sempre tectônico sob a forma de falhas de empurrão, configurando estruturação em escamas tectônicas (Abreu et al. 1986; Hartman 1987 e Abreu 1993).

Na região da cidade do Serro esta sequência foi dividida por Uhlein (1982) em duas unidades : uma basal, representada por xistos magnesianos correspondentes a uma unidade ultrabásica, na qual ocorrem os cromititos, e outra de tôpo, representada por metassedimentos químicos e detríticos. A estes corpos ultrabásicos portadores de cromita várias interpretações foram atribuídas por diversos pesquisadores, levando-se em conta fatores químicos, litológicos, tectônicos, estratigráficos e metalogenéticos:

- intrusões ígneas, ou seja, complexo tipo estratiforme diferenciado "in situ” (Queiróz 1986; Cassedane \& Chaves 1991);

- intrusões tectônicas, ou seja, complexo tipo alpino (Grossi Sad \& Vaz de Melo 1969; Renger 1972; Biondi et al. 1978 e Inda et al. 1984).

- origem efusiva associada à sequência do tipo "greenstone belt" (Uhlein 1982; Assis 1982; Uhlein \& Dardene 1984; Uhlein et al. 1986).

A pesquisa e a interpretação do interrelacionamento entre as rochas que compõem esta seqüência são de fundamental importância para as tentativas de correlação entre a Cordilheira do Espinhaço e o Quadrilátero Ferrífero (Assis \& Marini 1983; Fogaça 1985). Além disto tal sistemática irá contribuir com subsídios para um maior conhecimento da evolução geológica regional, que vem dando origem à criação de novos modelos evolutivos onde se destacam Abreu et al. (1989) e Marshak \& Alkmin (1989).

Mais para o sul ocorre outra sequência vulcanosedimentar, que pode estar relacionada com a Sequência do Serro. Encontra-se localizada na região do Morro do Pilar e é denominada de Sequência VulcanoSedimentar Rio Mata Cavalo. O precambriano desta região é dividido em três unidades estratigráficas (Chapadeiro et al. 1987) :

- Complexo Gnáissico - constituído essencialmente por gnaisses mais ou menos milonitizados;

- Sequência Vulcano-Sedimentar ( Rio Mata Cavalo) - composta por rochas ultramáficas e metassedimentos detríticos e químicos;

- Sequência Clasto-Química - subdividida em três unidades : Uma inferior constituída de quartzitos e xistos-filitos, outra média representada por itabiritos e por fim, uma unidade superior composta por quartzitos e xistos-filitos.

Os contatos entre estas unidades são sempre tectônicos, originados por cisalhamento de direção meridiana e mergulho para leste. Os mecanismos que atuaram na formação das faixas de cisalhamento foram também responsáveis pela inversão estratigráfica das unidades. O empilhamento tectônico e a pouca evidência das estruturas primárias não possibilitam o estabelecimento definitivo do quadro estratigráfico local (Ulhein et al. 1986; Knauer 1990).

Intrusivas básicas concordantes ou não ocorrem seccionando essas unidades. Esses corpos apresentamse fortemente metamorfizados, localizando-se imediatamente a leste da região da Serra do Espinhaço. Corpos similares a estes também são descritos em uma faixa relativamente estreita de aproximadamente $10 \mathrm{~km}$ de largura, estendendo-se desde Morro do Pilar ao sul, passando por Conceição do Mato Dentro e seguindo até Rio Vermelho ao norte. Esta faixa apresenta continuidade de no mínimo $125 \mathrm{kms}$ na direção aproximadamente Norte-Sul, desviando-se para nordeste na sua porção mais setentrional.

As ocorrências de platina em aluviões e preenchendo fraturas em quartzitos são reconhecidas quase sempre associadas ao paládio, próximo às localidades de Serro, Conceição do Mato Dentro e Morro do Pilar. O modo de ocorrência e a associação mineralógica nas rochas primárias não são conhecidas, porém pode-se admitir sua origem a partir das rochas ultrabásicas ( Belezkij \& Guimarães 1959).

\section{SEQUÊNCIAS METAMÁFICO/ ULTRAMÁFICAS}

\section{Serro e Alvorada de Minas}

As rochas meta-ígneas, bem como os metassedimentos associados, incluindo as formações ferríferas bandadas e os metassedimentos detríticos, foram definidas como Sequência Serro (Abreu et al. 1989), objetivando substituir a antiga designação de Sequência Vulcano-Sedimentar do Serro (Uhlein 1982), fato discutido amplamente por Knauer (1990). Vários corpos de cromitito, lenticulares, ocorrem associados a estas unidades, e foram alvo deste estudo. O principal depósito é o do Morro do Cruzeiro, situado no limite norte do perímetro urbano da cidade do Serro, onde a lente de cromitito acha-se encaixada em clorita xistos, talco xistos e serpentinitos, pela ordem de importância. Pela paragênese observada, o processo metamórfico atuou sobre rochas de natureza peridotito-piroxenítica com grau baixo a médio. A paragênese: serpentina (antigoritas) + clorita + talco + actinolita + antofilita é indicativa de, no mínimo, um metamorfismo de fácies anfibolito inferior.

Tanto os corpos de cromitito do Serro quanto os de Alvorada de Minas (Corpo Fazenda da Lagoa), refletem o caráter alóctone da sequência máfico/ultramáfica, exibindo cisalhamento com direção aproximada N-S e mergulhos para leste-sudeste. Tal tectonismo provocou a colocação de membros metassedimentares em contato com as metaultramáficas, os quais representam segundo Knauer (1990), grandes intercalações tectônicas. Apesar disso, pesquisadores tais como Cassedane \& Chaves (1991) acreditam que o corpo do Serro 
corresponda a um Complexo Estratiforme, tomando por base as características de seus cromititos e a composição das cromitas, comparando-o com o depósito de Selukwe (Zimbabwe). Por sua vez Uhlein et al.(1983), apesar de considerarem o Maciço do Serro como uma sequência vulcano-sedimentar, concluem que os dados obtidos também são comparáveis àqueles correspondentes aos depósitos de cromita de Munro Township (Canadá), os quais se encontram associados ao complexo intrusivo acamadado.

É possível concluir, em função do exposto, que todos os maciços situados na porção centro-norte do Estado de Minas Gerais, onde se encontram os corpos do Serro e de Alvorada de Minas, apresentam formas alongadas, onde a maior dimensão está paralelizada à direção da foliação regional. Além disso possuem posição estratigráfica mais ou menos bem definida no interior de horizontes metaperidotíticos, gradação de minério disseminado para maciço (embora localizadamente, ocorrem alternâncias entre minério maciço e disseminado), bem como variação na granulação dos cristais de cromita e relação $\mathrm{Cr} / \mathrm{Fe}$ baixa (média aproximada de 2,0, similarmente ao corpo do Esbarro no Complexo de Tróia, Angeli 1993). Assim parecem corresponder a fragmentos de um complexo estratiforme diferenciado. Processos deformacionais e metamórficos pós-magmáticos, foram responsáveis pelas feições encontradas atualmente nos níveis de cromititos, principalmente com relação aos aspectos texturais dos mesmos e à composição química das cromitas.

\section{Morro do Pilar}

As unidades metamáfico-ultramáficas na região de Morro do Pilar foram denominadas de Sequência Vulcano-Sedimentar do Rio Mata Cavalo por Uhlein et al. (1983). Segundo estes autores esta sequência se constitui de metaultramáficas de baixo grau, encerrando intercalações de metassedimentos (químicos e detríticos), podendo corresponder a um greenstone belt arqueano. Estes autores bem como Uhlein et al. (1983) estabelecem uma comparação entre esta seqüência com aquelas unidades encontradas na região do Quadrilátero Ferrífero, mais para o sul. Desta forma fazem correlação entre a Seqüência Vulcano-Sedimentar do Serro e o Grupo Nova Lima, o qual apresenta idades entre 2, 8 e 2, 4 b.a. Segundo Uhlein et al (1983) as rochas serpentiníticas apresentam provável textura spinifex reliquiar. Além destas publicações, soma-se a de Uhlein et al. (1986), onde fica caracterizada uma correlação entre as Sequiências Vulcano Sedimentares do Serro e do Mata Cavalo com o Grupo Nova Lima.

Chapadeiro et al. (1987) subdividem as unidades litológicas precambrianas da região em três grandes domínios, todos apresentando contatos tectônicos entre si(cisalhamento de direção meridiana com mergulho para leste), quais sejam : Complexo Gnáissico (embasamento cristalino milonitizado) ; sequência Vulcano-Sedimentar do Rio Mata Cavalo e Sequência
Clasto-Química (itabiritos e metassedimentos). O tectonismo compressivo não coaxial produziu um encurtamento crustal em direção ao cráton do São Francisco (Borba et al.1987).

A Sequência Vulcano-Sedimentar do Rio Mata Cavalo é composta por metaultramáficas e metassedimentos detríticos e químicos, estes últimos representados por formações ferríferas bandadas com intercalações de metacherts. A unidade metaultramáfica é constituída por talco-clorita xistos, talco-tremolitaactinolita xistos, clorita xistos, talco xistos, talcoserpentina xistos e serpentinitos, dentre outras variedades menos frequentes.Localmente registram-se a presença de vênulas milimétricas a centimétricas de crisotila nas rochas serpentiníticas, bem como de relictos de olivina no estudo petrográfico das metaultramáficas. A paragênese encontrada indica que estas rochas foram submetidas a um metamorfismo de baixo grau (fácies dos xistos verdes, atingindo até o fácies epidoto-anfibolito), correspondendo ao produto de alteração de rochas de composição peridotítica.

\section{O QUIMISMO DAS CROMITAS}

\section{Serro e Alvorada de Minas}

Os cromititos presentes nestas duas áreas variam de maciços a disseminados, apresentando em média 65 a $75 \%$ de cromita, com grande parte de clorita intersticial (kammererita) e menos frequentemente serpentina (antigorita). Comumente encontram-se cromitas bastante fraturadas, onde a textura "pull apart" predomina, denotando caráter protomilonítico ao cromitito. Minerais acessórios frequentemente observados em seções polidas são: magnetita e mais raramente rutilo e ilmenita. Alguns cristais de cromita acham-se sob a forma de inclusões em ilmenita, fato mais comumente verificado em rochas serpentiníticas. Sulfetos também ocorrem, quer como inclusões nas cromitas, quer imersos na ganga silicática, e correspondem principalmente a pirita, calcopirita e mais raramente a bornita, calcocita e covelita. Em geral, todos estes minerais sulfetados se apresentam com maior abundância em rochas com matriz carbonática. A grande concentração de carbonatos (com destaque para siderita, ankerita e magnesita) indica que durante a alteração das cromitas, o cromo foi liberado para a formação das kammereritas, contando com a participação de fluídos externos. Tal fato é observado em seções polidas e delgadas, onde observa-se claramente íntima associação entre as cromitas e as kammereritas, bem como entre estes cristais e a fase carbonática, a qual também contém cromo.

O minério apresenta granulação fina, com cristais de cromita euhedrais a subhedrais, variando entre 0,1 e $0,3 \mathrm{~mm}$, e exibe em algumas porções textura xenomórfica a hipidiomórfica (Zapparoli et al. 1995). As cromitas, em sua grande maioria exibem forte zoneamento, mesmo quando se observam os 
fragmentos resultantes do intenso fraturamento, que é marcado em geral por três zonas distintas, quer seja pela reflectância distinta, quer seja pela diferença composicional. De modo geral, o núcleo dos cristais apresenta composição mais cromífera (ferro-cromitas e alumino-cromitas), e suas bordas são mais ferríferas (ferritcromitas). Alguns cristais chegam a apresentar uma delgada borda composta essencialmente por magnetita.

A composição química das cromitas do Corpo do Morro do Cruzeiro (Serro) e do Corpo da Fazenda da Lagoa (Alvorada de Minas) - Tabela 1, quando plotada no diagrama $\mathrm{Cr}-\mathrm{Fe}^{3+}-\mathrm{Al}$ (Figura 2), mostra que o trend de variação química acompanha o processo de alteração hidrotermal. Os dados apresentados para $\mathrm{Fe}_{2} \mathrm{O}_{3}$ foram calculados de acôrdo com o método proposto por Carmichael (1967). Assim as cromitas destes maciços situam-se predominantemente no campo das ferrocromitas e das cromo-magnetitas. Desta forma, em função das transformações ocorridas nos cromititos do corpo do Morro do Cruzeiro, pela alteração metamórfica-hidrotermal, fica difícil uma avaliação segura dos processos ocorridos. O zoneamento químico observado no interior dos grãos de cromita mostra similaridade com aquele observado no Complexo de Tróia (Corpo do Esbarro - Pedra Branca, CE) e em Ipanema (Maciço de Santa Cruz - Ipanema, MG), de onde já se tem algumas referências na literatura (Simões et al. 1992; Angeli 1993; Fleet et al. 1993 , Nogueira Neto et al. 1994 e Angeli 1996).

Vários cristais de cromita apresentam-se margeados por clorita, bem como contém inclusões desta fase mineral, a qual recepcionou o cromo extraído das cromitas devido ao hidrotermalismo, formando as kammereritas. Trata-se de um evento genético similar ao que ocorreu em Pedra Branca (Complexo de Tróia Ceará), que foi estudado por Fleet et al. (1993). Caso idêntico também se registra na Carolina do Norte (Lipin 1984). Normalmente nas bordas de ferritcromita são observadas inclusões de serpentina e de carbonatos, e em alguns casos de platinóides.

No Complexo Acamadado de Stillwater (MontanaUSA) o nível de cromitito maciço apresenta em seu contato basal concentração de platinóides (Murck 1985). Próximo desta porção a rocha apresenta textura cumulática, onde silicatos intercumulus (olivinas e ortopiroxênios) não estão mais presentes na rocha, fato que promoveu o enriquecimento em platinóides, e que é atribuído pela autora à ação hidrotermal, ou a um novo pulso magmático. Esta última hipótese é também defendida por Cassedane \& Chaves (1991) para o cromitito do corpo do Morro do Cruzeiro. A argumentação se baseia na condução dos platinóides disseminados na rocha pelo fluído hidrotermal, os quais enriquecem as soluções e se concentram durante o transporte.

\begin{tabular}{|c|c|c|c|c|c|c|c|c|c|c|c|c|}
\hline \multirow{2}{*}{\begin{tabular}{|c|} 
Corpo \\
$\begin{array}{c}\text { Amostra } \\
\%\end{array}$ \\
\end{tabular}} & \multicolumn{10}{|c|}{ Serro - Morro do Cruzeiro } & \multicolumn{2}{|c|}{$\begin{array}{c}\text { Alvorada de } \\
\text { Minas } \\
\text { Faz. da Lagoa }\end{array}$} \\
\hline & $07 / 1 \mathrm{a}$ & 07/1b & $07 / 1 c$ & $07 / 2 a$ & $07 / 2 b$ & $07 / 2 c$ & 07/3a & $07 / 4 a$ & $07 / 4 b$ & $07 / 4 c$ & $01 / 1 a$ & $01 / 1 b$ \\
\hline $\mathrm{TiO}_{2}$ & 1.02 & 0.12 & 0.05 & 1.00 & 0.14 & 0.03 & 0.32 & 1.42 & 0.10 & 0.01 & 0.25 & 0.10 \\
\hline $\mathrm{Al}_{2} \mathrm{O}_{3}$ & 8.17 & 0.60 & 0.04 & 8.33 & 0.77 & 0.03 & 8.32 & 10.52 & 0.86 & 0.02 & 10.76 & 0.75 \\
\hline $\mathrm{FeO}$ & 31.72 & 31.67 & 31.06 & 31.94 & 31.21 & 31.07 & 30.78 & 32.71 & 31.08 & 31.33 & 29.71 & 32.02 \\
\hline $\mathrm{Fe}_{2} \mathrm{O}_{3}$ & 7.18 & 22.07 & 54.04 & 6.19 & 22.24 & 57.01 & 7.10 & 5.93 & 23.33 & 59.01 & 7.63 & 21.26 \\
\hline $\mathrm{Cr}_{2} \mathrm{O}_{3}$ & 48.46 & 45.85 & 14.66 & 50.21 & 44.61 & 11.76 & 49.23 & 47.05 & 43.76 & 9.40 & 44.34 & 43.78 \\
\hline $\mathrm{MnO}$ & 0.40 & 0.40 & 0.12 & 0.37 & 0.40 & 0.11 & 0.38 & 0.45 & 0.52 & 0.10 & 0.40 & 0.53 \\
\hline $\mathrm{MgO}$ & 0.90 & 0.10 & 0.01 & 1.05 & 0.16 & 0.01 & 0.98 & 0.96 & 0.21 & 0.04 & 3.40 & 0.15 \\
\hline Total & 97.85 & 100.81 & 99.98 & 99.09 & 99.53 & 100.02 & 97.11 & 99.04 & 99.86 & 99.91 & 96.49 & 98.59 \\
\hline \multicolumn{13}{|c|}{ Cátions } \\
\hline Al & 2.805 & 0.210 & 0.014 & 2.819 & 0.273 & 0.011 & 2.874 & 3.527 & 0.304 & 0.007 & 3.658 & 0.270 \\
\hline $\mathrm{Ti}$ & 224 & 0.027 & 0.012 & 0.216 & 0.032 & 0.007 & 0.071 & 0.304 & 0.023 & 0.002 & 0.054 & 0.023 \\
\hline $\mathrm{Fe}^{2+}$ & 7734 & 7.885 & 7.945 & 7.677 & 7.861 & 7.958 & 7.550 & 7.789 & 7.800 & 8.050 & 7.173 & 8.174 \\
\hline $\mathrm{Fe}^{3+}$ & 1574 & 4.939 & 12.426 & 1.337 & 5.035 & 13.126 & 1.565 & 1.269 & 5.263 & 13.630 & 1.656 & 4.878 \\
\hline $\mathrm{Cr}$ & 11.158 & 10.779 & 3.541 & 11.395 & 10.610 & 2.844 & 11.402 & 10.579 & 10.370 & 2.281 & 10.109 & 10.553 \\
\hline $\mathrm{Mn}$ & 99 & 0.101 & 0.031 & 0.090 & 0.102 & 0.029 & 0.094 & 0.109 & 0.132 & 0.026 & 0.098 & 0.137 \\
\hline$M g$ & 391 & 0.044 & 0.005 & 0.450 & 0.072 & 0.005 & 0.428 & 0.407 & 0.094 & 0.018 & 1.463 & 0.068 \\
\hline
\end{tabular}

Tabela 1: Resultados analíticos por microssonda eletrônica de cromitas dos corpos Morro do Cruzeiro (Serro) e Fazenda da Lagoa (Alvorada de Minas).

Nota: A simbologia das amostras indicam: primeiro número $=n^{\circ}$ da amostra; segundo número $=n^{\circ}$ do cristal; letras $a, b, c=$ núcleo, zona intermediária e borda do cristal, respectivamente.

Table 1: Analytical results by eletronic microprobe of chromites from Morro do Cruzeiro (Serro) and Fazenda da Lagoa (Alvorada de Minas) bodies.

Note: The simbology of the samples indicates: first number = sample number; second number =crystal number; $a, b, c$ letters $=$ core, intermediate zone and border of the crystal, respectively. 


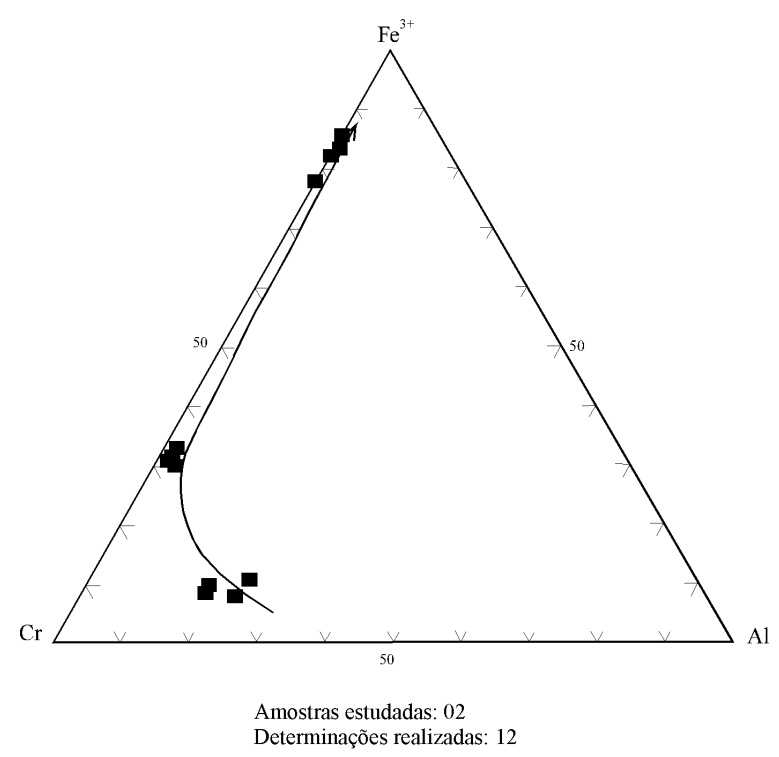

Figura 2: Diagrama ternário mostrando a alteração causada pelo hidrotermalismo/metamorfismo nos cristais de cromita dos cromititos do Serro e de Alvorada de Minas.

Nota: a seta indica o trend de alteração dos cristais. Figure 2:Ternary Diagram showing the alteration owing yo hydrotermalism/metamorphism in the chromite crystals of the chromites from Serro and Alvorada de Minas.

Note: The arrow indicates the alteration trend of the crystals.

\section{Morro do Pilar}

Na Sequência Vulcano-Sedimentar do Rio Mata Cavalo não ocorrem cromititos, estando presentes apenas cromitas como minerais acessórios, as quais foram da mesma forma estudadas nesta pesquisa. As cromitas ocorrem com maior frequência nos serpentinitos, tremolita-actinolita-serpentina xistos e serpentina-talco xistos. Outros opacos presentes nestas rochas são: magnetita e ilmenita. Em algumas amostras observam-se exsoluções de magnetita em ilmenita. Sulfetos são raros e ocorrem com maior frequência associados à matriz silicática, tendo sido reconhecidos : pirita, calcopirita, pirrotita e pentlandita, citados em ordem de importância quantitativa.

As cromitas apresentam-se sob forma de cristais subhedrais a anedrais, encontram-se intensamente fraturadas e exibem forte zoneamento. Na Tabela 2 são apresentados os resultados obtidos para 11 determinações realizadas nos cristais de cromita que exibem claramente tal zoneamento. Pode-se observar na Figura 3, que as cromitas acessórias presentes nas rochas metaultramáficas da Sequência VulcanoSedimentar do Rio Mata Cavalo, apresentam trend de variação química que segue desde o campo das alumino-cromitas até o das cromo-magnetitas. Ocorre um gap entre os alumino-cromitas e as magnetitas e possivelmente com maior número de análises o trend seria completo. Há vários pontos que se concentram no polo $\mathrm{Fe}^{3+}$ indicando estreita interação entre o fluído

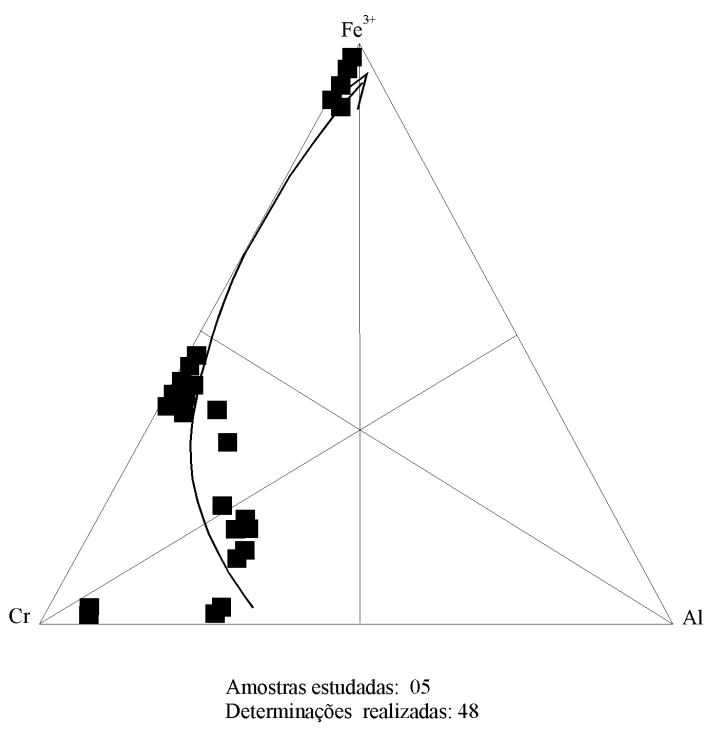

Figura 3: Diagrama ternário mostrando a alteração imposta pelo hidrotermalismo/metamorfismo nas cromitas presentes nos serpentinitos da sequência vulcano-sedimentar do Rio Mata Cavalo (Morro do Pilar - MG).

Nota: a seta exibe o trend de alteração dos cristais. Figure 3: Ternary Diagram showing the alteration due to hydrotermalism/metamorphism in the accessory chromites in the serpentinites of the volcano sedimentary sequence from Rio Mata Cavalo (Morro do Pilar - MG).

Note: The arrow exhibites the alteration trend of the crystals.

hidrotermal e os cristais de cromita. Esta interpretação é calcada principalmente pela microscopia por luz refletida onde se observa claramente as bordas dos cristais com propriedades ópticas de magnetita e os seus núcleos já exibem características das cromitas primárias (pouca ou nenhuma alteração). Desta forma as cromitas primárias pertencem composicionalmente à série das alumino-cromitas, que também correspondem ao quimismo do núcleo dos cristais zonados. De modo geral observou-se que o conteúdo em $\mathrm{Al}_{2} \mathrm{O}_{3}$ exibe extrema variabilidade, e em geral apresenta maiores concentrações no núcleo dos cristais, onde exatamente o Fe é mais baixo. Por sua vez o Fe apresenta valores crescentemente mais elevados em direção à borda dos cristais.

Pelas características registradas, relacionamento entre as diferentes zonas, variação na coloração das mesmas, interrelacionamento com bordas e fraturas e finalmente o quimismo, observa-se que nas bordas dos cristais se tem a presença marcante de $\mathrm{Fe}^{3+}$, ao passo que nos núcleos já predomina o Fe de valência menor. Desta maneira, os cristais completamente alterados, bem como as bordas das cromitas zonadas, apresentam composição próxima da magnetita. O níquel também apresenta variações significativas em seu conteúdo (em algumas amostras), quando se parte do núcleo para a borda dos cristais, onde geralmente aumenta de teor neste sentido. Com isto pode-se concluir que nas 


\begin{tabular}{|c|c|c|c|c|c|c|c|c|c|c|c|}
\hline \multirow{2}{*}{$\begin{array}{c}\text { Corpo } \\
\begin{array}{c}\text { Amostras } \\
\%\end{array}\end{array}$} & \multicolumn{11}{|c|}{$\begin{array}{c}\text { Porção Ultramáfica da Sequência Vulcano-Sedimentar do Rio Mata Cavalo } \\
\text { (Morro do Pilar) }\end{array}$} \\
\hline & $09 / 1 a$ & $09 / 1 b$ & $09 / 1 \mathrm{c}$ & $13 / 1 a$ & $13 / 1 b$ & $13 / 1 \mathrm{c}$ & $13 / 5 a$ & $13 / 5 b$ & $13 / 5 c$ & $13 / 2 a$ & $13 / 2 c$ \\
\hline $\mathrm{Al}_{2} \mathrm{O}_{3}$ & 8.25 & 0.26 & 0.05 & 11.46 & 1.08 & 0.01 & 10.59 & 3.86 & 0.06 & 6.03 & 0.02 \\
\hline $\mathrm{Cr}_{2} \mathrm{O}_{3}$ & 41.62 & 35.91 & 6.03 & 41.23 & 36.73 & 2.47 & 41.27 & 35.75 & 3.99 & 37.04 & 2.72 \\
\hline $\mathrm{Fe}_{2} \mathrm{O}_{3}$ & 14.60 & 30.83 & 62.99 & 8.80 & 28.83 & 62.58 & 11.88 & 26.09 & 61.29 & 22.52 & 62.57 \\
\hline $\mathrm{FeO}$ & 30.15 & 30.04 & 31.47 & 31.30 & 29.95 & 29.21 & 31.14 & 31.01 & 29.37 & 30.26 & 29.39 \\
\hline $\mathrm{MgO}$ & 0.38 & 0.14 & 0.00 & 0.66 & 0.16 & 0.00 & 0.65 & 0.27 & 0.05 & 0.33 & 0.00 \\
\hline $\mathrm{TiO}_{2}$ & 0.56 & 0.52 & 0.25 & 1.81 & 0.52 & 0.04 & 1.28 & 0.97 & 0.05 & 0.53 & 0.07 \\
\hline $\mathrm{MnO}$ & 0.87 & 0.85 & 0.17 & 1.01 & 0.93 & 0.07 & 0.86 & 0.77 & 0.10 & 0.80 & 0.09 \\
\hline $\mathrm{ZnO}$ & 1.54 & 0.94 & 0.08 & 1.45 & 0.98 & 0.18 & 1.65 & 0.96 & 0.07 & 1.35 & 0.15 \\
\hline $\mathrm{NiO}$ & 0.11 & 0.10 & 0.14 & 0.05 & 0.08 & 0.11 & 0.09 & 0.06 & 0.11 & 0.10 & 0.12 \\
\hline Total & 98.08 & 99.59 & 101.18 & 97.77 & 99.26 & 94.67 & 99.41 & 99.74 & 95.09 & 98.96 & 95.13 \\
\hline \multicolumn{12}{|c|}{ Cátions } \\
\hline $\mathrm{Al}$ & 2.854 & 0.093 & 0.018 & 3.895 & 0.385 & 0.004 & 3.564 & 1.349 & 0.023 & 2.098 & 0.008 \\
\hline $\mathrm{Cr}$ & 9.659 & 8.615 & 1.448 & 9.402 & 8.795 & 0.635 & 9.320 & 8.384 & 1.020 & 8.648 & 0.696 \\
\hline $\mathrm{Fe}^{3+}$ & 3.225 & 7.040 & 14.398 & 1.910 & 6.571 & 15.321 & 2.553 & 5.824 & 14.914 & 5.004 & 15.241 \\
\hline $\mathrm{Ti}$ & 0.124 & 0.119 & 0.057 & 0.393 & 0.118 & 0.010 & 0.275 & 0.216 & 0.012 & 0.118 & 0.017 \\
\hline $\mathrm{Mg}$ & 0.166 & 0.063 & 0.000 & 0.284 & 0.072 & 0.000 & 0.277 & 0.119 & 0.024 & 0.145 & 0.000 \\
\hline $\mathrm{Fe}^{2+}$ & 7.401 & 7.623 & 7.994 & 7.550 & 7.586 & 7.948 & 7.438 & 7.693 & 7.943 & 7.473 & 7.956 \\
\hline $\mathrm{Mn}$ & 0.216 & 0.218 & 0.044 & 0.247 & 0.239 & 0.019 & 0.208 & 0.193 & 0.027 & 0.200 & 0.025 \\
\hline $\mathrm{Zn}$ & 0.334 & 0.211 & 0.018 & 0.309 & 0.219 & 0.043 & 0.348 & 0.210 & 0.017 & 0.294 & 0.036 \\
\hline $\mathrm{Ni}$ & 0.026 & 0.024 & 0.034 & 0.012 & 0.019 & 0.029 & 0.021 & 0.014 & 0.029 & 0.024 & 0.031 \\
\hline
\end{tabular}

Tabela 2: Resultados analíticos por microssonda eletrônica de cromitas acessórias dos serpentinitos da sequência vulcano-sedimentar do rio Mata Cavalo (Morro do Pilar).

Nota: A simbologia das amostras indicam: primeiro número $=n^{o}$ da amostra; segundo número $=n^{o}$ do cristal; letras $a, b$, c minúsculas = núcleo, zona intermediária e borda do cristal, respectivamente.

Table 2: Analytical results by eletronic microprobe of accessory chromites of the serpentinites from volcanosedimentary sequence of Rio Mata Cavalo (Morro do Pilar).

Note: The simbology of the samples indicates: first number = sample number; second number = crystal number; $a, b, c=$ core, intermediate zone and border of the crystal, respectively.

porções onde ocorreu a maior interação entre o fluído hidrotermal e os cristais de cromita a alteração foi mais intensa, promovendo um crescimento nos valores das relações $\mathrm{Cr} /(\mathrm{Cr}+\mathrm{Al})$ e $\mathrm{Mg} /\left(\mathrm{Mg}+\mathrm{Fe}^{2+}\right)$. Isto é mostrado por vários pesquisadores, entretanto Burkhard (1993) mostra que existem cromitas acessórias mais refratárias a este processo, notadamente aquelas mais ricas em $\mathrm{Al}$ e $\mathrm{Mg}$, e deficientes em Fe.

Alguns cristais de magnetita exibem textura esquelética de cromita com borda alterada para ferritcromita, bem como apresentam conteúdos elevados em cromo. Desta maneira pode-se concluir que existem duas gerações de magnetita, uma originada pelo próprio processo de serpentinização das rochas, e outra formada pela alteração de cromitas primárias. Cabe observar que um pequeno cristal, correspondente de fato a uma liga metálica com alto Irídio (Platinirídio com $72 \%$ Ir e $14 \%$ Pt) foi encontrado em seção polida e posteriormente analisado por microssonda eletrônica. Esta liga encontra-se inclusa em cristal de cromomagnetita.

\section{CONSIDERAÇÕES FINAIS}

A composição química das cromitas apresenta na realidade um descréscimo na relação $\mathrm{Cr} / \mathrm{Fe}$, quando se parte do centro para a borda dos cristais. Desta forma tem-se : no núcleo dos cristais - cromita, na porção intermediária - ferritcromita (ferro-cromita) e na borda pode-se chegar até magnetita. Tal constatação é observada óptica e quimicamente, tanto nos cromititos do Serro e de Alvorada de Minas, quanto nas cromitas 
acessórias dos serpentinitos do Morro do Pilar. Em vários complexos máfico/ultramáficos tal fato é constatado e foi alvo de publicações, podendo ser citados: Red Lodge District - U.S.A. (Loferski \& Lipin 1983); Blue Ridge - U.S.A. (Lipin 1984); Edessa Grécia (Michailidis 1990); Hochgrossen e Kraubath Áustria (Thalhammer et al. 1990); Troodos - Chipre (McElduff \& Stumpfl 1991); Thetford Mines-Canadá (Gauthier et al. 1990); Josephine Ophiolite - U.S.A. (Kimball 1990); Sykesville District - U.S.A. (Wylie et al.1987); Alpes suiços e itálicos (Burkhard 1993) e Jinchuan - China (Yang et al. 1994).

Pode ser constatado que associados à modificação na relação $\mathrm{Cr} / \mathrm{Fe}$, existem também alterações principalmente no conteúdo em $\mathrm{MgO}, \mathrm{Al}_{2} \mathrm{O}_{3}, \mathrm{MnO}$ e $\mathrm{TiO}_{2}$ (que decresce em direção às porções mais ricas em Fe). O que nos fica difícil de determinar é a forma sob a qual ocorreu o processo. Grande parte dos autores advoga a alteração metassomática por "difusão em estado sólido" em presença de fase fluída. Outros autores já sugerem a atuação de processo que modifica a composição das cromitas por reequilíbrio subsólido com a fase silicática-olivinas (Engi 1983).

Químicamente pode-se assumir que a composição primária das cromitas modifica-se em função do grau de alteração hidrotermal, que em grande parte dos cristais é elevado. Entretanto, encontram-se também cristais com menor grau de alteração com núcleos preservados e bordas bastante alteradas, onde se observa uma elevação nas relações $\mathrm{Cr} / \mathrm{Cr}+\mathrm{Al}$ e $\mathrm{Fe}_{2}+/ \mathrm{Fe}_{2}++\mathrm{Mg}$ , fato também verificado no Complexo de Tróia (Angeli 1993). Desta forma a composição média do cromitito realmente se situa no campo das cromitas ferro aluminosas. Para mobilizar o $\mathrm{Al}^{3+}$ parece que se precisaria de temperaturas mais elevadas, que aquelas comumente reconhecidas no processo de serpentinização, ou seja $200^{\circ} \mathrm{C}$.

A paragênese verificada aponta contato entre os cristais de cromita predominantemente com cloritas, e com menor frequência com serpentina e talco (Zapparoli et al. 1995). Os cristais de clorita evidenciam o fenômeno, posto que apresentam-se enriquecidos em cromo, tratando-se de kammereritas, que geneticamente se relacionam ao processo de alteração hidrotermal. Desta forma deve ter ocorrido uma forte interação entre o fluído hidrotermal e a cromita primária, conforme apontado por Wylie et al. (1987), entretanto existem porções dos cromititos preservadas desta pronunciada alteração. Pode-se verificar que as porções dos corpos de cromititos que apresentam maior alteração hipógena exibem cristais zonados, além de maior concentração de kammereritas, o que comprova tal hipótese.

Com a atuação do evento metamórfico/hidrotermal, as rochas estudadas, e em especial os cromititos do Morro do Cruzeiro exibem texturas que indicam reequilíbrio metamórfico e composição química que refletem a participação de fluídos externos. Apesar da textura "pull apart" ser predominante, deve-se ressaltar que textura hipidiomórfica e granonematoblástica foram também encontradas. A paragênese neoformada é bastante hidratada com predomínio de clorita e talco com grande quantidade de carbonatos. Entretanto encontram-se relictos de material mais preservados nas porções centrais dos leitos de cromititos (menor grau de deformação e metamorfismo). Os próprios cristais de cromita exibem perda em cromo (química e microscopicamente pelo zoneamento observado), o qual foi incorporado pelas kammereritas. O que nos parece até o presente, com base nos dados disponíveis, é que o Complexo do Serro (Morro do Cruzeiro) corresponde a um Maciço Máfico/Ultramáfico intrusivo com posterior deformação e metamorfismo (Figura 4).

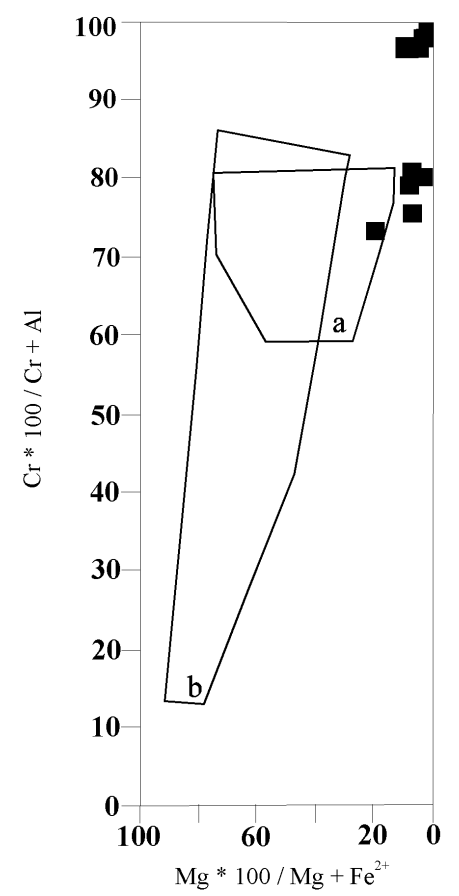

Figura 4: Campos de variação composicional das cromitas do Serro e de Alvorada de Minas.

a) Campo dos Complexos Estratiformes;

b) Campo dos Complexos Alpinos.

Figure 4: Composicional variation fields of chromites from Serro and Alvorada de Minas.

a) stratiform complexes field;

b) alpyne complexes field.

Mesmo levando-se em consideração a alteração sofrida pelos grãos de cromita, observa-se nesta figura que a composição química dos cristais fica bastante próxima do campo dos complexos estratiformes (à exceção daqueles com elevado grau de alteração). Entretanto os problemas que se encontram são similares àqueles apontados por Loferski \& Lipin (1983) para os corpos ultramáficos de Red Lodge (Montana - USA). Estes autores mostram que leitos de cromititos metamorfoseados apresentam evidências que ora permitem colocá-los como depósitos estratiformes ora como do tipo alpino. No caso dos depósitos de Red Lodge eles acreditam na hipótese de que os corpos ultramáficos faziam parte de um complexo tipo 
estratiforme, o qual foi fragmentado tectonicamente e submetido a metamorfismo regional. Assim acreditamos que Serro (corpo Morro do Cruzeiro) e Alvorada de Minas (corpo Fazenda da Lagoa) tenham evolução geológica similar, onde os cromititos estudados apresentam cristais de cromita com composição próxima do campo dos complexos tipo estratiforme.

É importante colocar que este estudo se faz importante para futuras pesquisas, as quais já estão sendo iniciadas, e que versam sobre a concentração de ouro e platinóides associada à alteração hidrotermal de cromititos, a exemplo do que vem apresentando Angeli (1996) para o Maciço de Santa Cruz (Complexo de Ipanema - MG). Elevadas razões de $(\mathrm{Pt}+\mathrm{Pd}) /(\mathrm{Os}+\mathrm{Ir}$ $+\mathrm{Ru}$ ) são características de depósitos que sofreram ação de processo hidrotermal (Rowell \& Edgar 1986), e também estão sendo determinadas pelo autor para as ocorrências estudadas no estado de Minas Gerais. No corpo do Morro do Cruzeiro (Serro) apenas uma amostra isolada forneceu valores anômalos em PGE (196 ppb de Ru e 72 ppb de Pd), porém carecem de significado científico.

No Complexo Máfico/Ultramáfico de Tróia (CE) foram encontrados por Angeli (1993) e Angeli et al. (1993) cristais de irídio-sperrilita ( $\left.\mathrm{Pt} \mathrm{As}_{2}\right)$ e de paládiohollingwortita ( $\mathrm{Rh}, \mathrm{Pt}, \mathrm{Ru}, \mathrm{Ir}$ ) As $\mathrm{S}$ em cromititos. Os PGE encontram-se inclusos nas bordas dos cristais de cromita (ferritcromita) e na matriz silicática (cloritas predominantemente). Já no Complexo Máfico/ Ultramáfico de Ipanema (Maciço de Santa Cruz), que tem características próximas de complexos tipo alpino, tem-se concentração de PGE e ouro no principal nível de cromitito associada às cromitas. Os elevados conteúdos em Au, Rn, Pt e Ir devem estar relacionados à alteração hidrotermal das cromitas e possivelmente se encontram alojados na estrutura cristalina destes cristais (Angeli 1996). Desta forma, maior volume de pesquisas deve ser realizado nas regiões do Serro, Alvorada de Minas e Morro do Pilar, com o objetivo de se localizar concentrações ou ocorrências de elementos do grupo da platina e ouro.

\section{AGRADECIMENTOS}

Seguem os agradecimentos do primeiro autor à Fundação de Amparo à Pesquisa do Estado de São Paulo (FAPESP) pelo suporte financeiro prestado por mais de um ano, quando da realização de Programa de Pós-Doutoramento no Canadá. Agradece também ao Prof. Dr. M.E. FLEET pelas discussões durante as pesquisas e ao Geólogo R.L. BARNETT pela sua ajuda durante os trabalhos com microssonda eletrônica no Depto. de Ciências da Terra da University of Western Ontario (London, ON-Canadá).

Também Nélson ANGELI expressa seus agradecimentos ao Prof. Dr. Alfredo FERRARIO da Università Degli Studi di Milano (Milano, Itália) e à Prof $^{a}$ Maria Ângela F. CÂNDIA pelos seus comentários e sugestões durante os trabalhos de campo na região pesquisada.

Finalmente os autores expressam seus agradecimentos a um "referee" do corpo consultivo da Geonomos, que nos forneceu valiosas sugestões e comentários sobre o artigo.

\section{REFERÊNCIAS BIBLIOGRÁFICAS}

ABREU, P.A.A.; FERNANDES, P.C. de O.; KNAUER, L.G.; HARTMAN, M.B.; DONATO, M.T. \& SCHORSCHER, H.D. (1986) Elementos da zona de cisalhamento dúctil da borda oriental da Serra do Espinhaço, Minas Gerais. Congr. Bras. Geol., 31º, Anais, Goiânia, 3: 1219-1231.

ABREU, P.A.A.; KNAUER, L.G.; HARTMAN, M.B.; SANTOS, G.G.V.dos; GUIMARÃES, G.G.; ABREU, F.R.de; SCHRANK, A. \& PFLUG, R. (1989) Estratigrafia, faciologia e tectônica do Supergrupo Espinhaço na região do Serro e Conceição do Mato Dentro, Minas Gerais, Brasil. Zbl.Geol.Paleont.,Teil I,H5/6: 857-873.

ABREU, P.A.A. (1993) A evolução geodinâmica sa Serra do Espinhaço Meridional, Minas Gerais, Brasil. Tese de Doutoramento. Freiburg (Alemanha) : $150 \mathrm{p}$.

ALAPIETI, T.T.; KUJANPAA, J.; LAHTINEN, J.J. \& PAPUNEN, H. (1989) The Kemi Stratiform Chromitite Deposit, Nothern Finland. Econ.Geol., 84: 1057-1077.

ANGELI, N. (1993) Alteração hidrotermal dos cromititos do Complexo Metamáfico/Ultramáfico de Tróia (CE) e o enriquecimento em platinóides. Simp.Geol.Nordeste, XV, Natal, SBG, Bol. 13: 166-168.

ANGELI, N.; FLEET, M.E.; KINGSTON, D.M. \& NOGUEIRA NETO, J.A. (1993) Ir-bearing sperrylite and Pd-bearing hollingworthite in chromitites from the Pedra Branca Complex, Ceará, Brazil. Brazilian Meeting on PGE, I, Ext. Abst. Vol., Brasília: 44-46.

ANGELI, N. (1996) Concentração de PGE e Au no cromitito do Maciço Máfico/Ultramáfico de Santa Cruz, Ipanema - Minas Gerais. Submetido à Geociências, São Paulo : 13p.

ASSIS, L.C. de (1982) Estratigrafia, tectônica e potencialidade mineral da Unidade Pré-Cambriana da região do Serro/ Quadrícula de Mato Grosso - Contribuição à controvérsia Espinhaço-Minas. Diss. de Mestrado, UnB, Brasília: 149 p.

ASSIS, L.C. \& MARINI, O.J. (1983) Contribuição à controvérsia Espinhaço-Minas. Simp. Geol. Minas Gerais, Anais, Belo Horizonte, 2: 361-375.

BELEZKIJ, V. \& GUIMARÃES, D. (1959) Sobre uma ocorrência singular de platina e geologia da parte central da Serra do Cipó. DNPM - DFPM, Bol., Rio de Janeiro, 106: 5-77.

BIONDI, J.C.; SCHRANK, A. \& PINHEIRO, J.C.F. (1978) Basitos e ultrabasitos do Espinhaço Meridional e região sul de Minas Gerais. Cong. Bras. Geol., 30, Anais, Recife, 3: 1213-1220.

BORBA, C.; CAMPOS, S. \& DOSSIN, I.A. (1987) Geologia da Região de Santo Antonio do Rio Abaixo (MG). Simp. Reg. Geol. de Minas Gerais, $4^{\circ}$, Anais, Belo Horizonte : 120-134.

BURKHARD, D.J.M. (1993) Accessory chromium spinels : Their coexistence and alteration in serpentinites. Geoch. Cosmoch. Acta, 57 : 1297-1306.

CARMICHAEL, I.S.E. (1967) The iron-titanium oxides of salic volcanic rocks and their associated ferromagnesium minerals. Contr. Miner. Petrol., $14: 36-64$.

CASSEDANE, J.P. \& CHAVES, M.L.S.C. (1991) Geologia e mineralogia da jazida de cromita do Morro do Cruzeiro, Serro - Minas Gerais. Inédito, Centro Geol. Eschwege, Diamantina: $10 \mathrm{p}$.

CHAPADEIRO, E.; SOARES, L.E.; MAGALHÃES, M.M.J.; PEREIRA, B.A.M.; ROQUE, C.N. \& PEREIRA, M.L.S. (1987) Geologia da Região de Morro Pilar - MG. Simp. Geol. Minas Gerais, IV, Anais, Belo Horizonte: 80-103.

ENGI, M. (1983) Equilibria involving Al-Cr spinel: Mg-Fe exchange with olivine. Experiments, thermodynamic analysis and consequences for geothermometry. Am.Jour.Sci., 283-A: 2971. 
EVANS, B.W. \& FROST, B.R. (1975) Chrome spinel in progressive metamorphism: A preliminary analysis. Geoch. Cosmoch. Acta, 39: 959 - 972.

FLEET, M.E.; ANGELI, N. \& PAN, Y. (1993) Oriented chlorite lamellae in chromite from the Pedra Branca Mafic-Ultramafic Complex, Ceará, Brazil. Am.Miner., 78: 68-74.

FOGAÇA, A.C.C. (1985) Serra do Espinhaço Meridional. Geologia dos Terrenos Arqueanos e Proterozóicos. Simp. Geol. Minas Gerais, $3^{\circ}$, Anais, Belo Horizonte, 5: 377-383.

GAUTHIER, M.; CORRIVAUX, L.; TROTTIER, L.J.; CABRI, J.; GILLES LAFLAMME, J.H. \& BERGERON, M. (1990) Chromitites platinifères des complexes ophiolitiques de l'EstrieBeauce, Appalaches du Sud Quebec.Miner.Dep., 25: 169-178.

GROSSI SAD, L.A.\& VAZ DE MELO, M.T.D. (1969) Geologia do Distrito do Serro, Minas Gerais, Brasil. Inédito, Relatório GEOSOL/DNPM, Belo Horizonte: 288 p.

HARTMAN, M.B. (1987) A Cordilheira do Espinhaço Meridional (MG): Registro de uma tectônica de colisão continental no final do Proterozóico. Centro Geol. Eschwege, Diamantina, Inédito: $2 \mathrm{p}$.

INDA, H.A.V.; SCHORSCHER, H.D.; DARDENNE, M.A.; SCHOBBENHAUS, C.; HARALYI, N.L.E.; BRANCO, P.C DE A. \& RAMALHO, R. (1984) O Cráton do São Francisco e a faixa de dobramentos Araçuaí. In: Geologia do Brasil, DNPM, Cap. V, Brasília: 193-248.

KIMBALL, K.L. (1990) Effects of hydrothermal alteration on the compositions of chromian spinels. Contr.Miner.Petrol., 105: 337-346.

KNAUER, L.G. (1990) Evolução Geológica do Pré-Cambriano da porção centro-leste da Serra do Espinhaço Meridional e metalogênese associada. Diss. Mestrado, IG/UNICAMP, Campinas : $298 \mathrm{p}$.

LIPIN, B.R. (1984) Chromite from the Blue Ridge Province of North Carolina. Am. Jour. Sci., 284 : 507-529.

LOFERSKI, P.J. \& LIPIN, B.R. (1983) Exsolution in metamorphosed chromite from the Red Lodge District, Montana. Am. Miner., 68: 777-789.

MARSHAK, K.S. \& ALKMIN, F.F. (1989) Proterozoic extension/ contraction tectonics of the Southern São Francisco Craton, Minas Gerais, Brazil. Tectonics, 3 (8): 555-571.

McELDUFF, B. \& STUMPFL, E.F. (1991) The chromite deposits of the Troodos Complex, Cyprus-Evidence for the role of a fluid phase accompanying chromite formations. Miner.Dep., 26: $307-318$

MICHAILIDIS, K.M. (1990) Zoned chromites with Mn-contents in the Fe-Ni-Cr-laterite ore deposits from the Edessa area in Northern Greece. Miner. Dep., 25: 190-197.

MURCK, B.W. (1985) Factors affecting the formation of chromite seams - Part II: Petrology and geochemistry of the $\mathrm{G}$ and $\mathrm{H}$ chromite seams in the Mountain View area of the Stillwater Complex, Montana - USA. PhD Thesis, Un. of Toronto, Canada: $94 \mathrm{p}$.

NOGUEIRA NETO, J.A.; ANGELI, N. \& VERÍSSIMO, C.U. (1994) Feições microtectônicas nos cromititos do Complexo de Santa Cruz (Ipanema-MG) e suas relações com gerações distintas de serpentina. Congr. Bras. Geol., 38º Bol. Res. Exp., Camboriú, 1: 661-662.
QUEIROZ, E.T. (1986) Geologia do cromo. In: Principais Depósitos Minerais do Brasil. DNPM/CVRD, Brasília, Vol. 2: 190-248.

RENGER, F. (1972) As rochas ultrabásicas da Serra do Espinhaço, Minas Gerais. Rev. Bras. Geoc., São Paulo, 2(3): 151-160.

ROWELL, W.F. \& EDGAR, A.D. (1986) Platinum group element mineralization in a hydrothermal $\mathrm{Cu}-\mathrm{Ni}$ sulfide occurrence, Rathban Lake, northeastern Ontario. Econ. Geol., 81(5): 12721277.

SIMÕES, S.J.C.; SCHRANK, A. \& ANGELI, N. (1992) Relações entre deformação e metamorfismo em rochas ultramáficas Sequência de Tróia (CE). Congr. Bras. Geol., 37º, Resumos, Bol., São Paulo: 239p.

STEVENS, R.E. (1944) Composition of some chromites of the Western hemisphere. Am. Miner., 29: 1-34.

TALKINGTON, R.W.; WATKINSON, D.H.; WHITTAKER, P.J. \& JONES, P.C.(1984) Platinum Group Minerals and other solid inclusions in chromite of ophiolite complexes : Occurrence and petrological significance. Tscherm. Miner. Petrol. Mitt., 32 : 285-301.

TARKIAN, M.; NAIDENOVA, E. \& ZHELYASKOVAPANAYOTOVA, M. (1991) Platinum- Group Minerals in chromitites from the Eastern Rhodope Ultramafic Complex, Bulgaria. Mineral. and Petrol., 44: 73-87.

THALHAMMER, O.A.R.; PROCHASKA, W. \& MUHLHANS, H.W. (1990) Solid inclusions in chrome - spinels and platinum group elements concentrations from the Hochgrossen and kraubath Ultramafic Massifs (Austria). Contr. Miner. Petrol., 105: 66-80.

THAYER, T.P. (1970) Chromite segregations as petrogenetic indicators. Geol. Soc. South Africa, Symp. on the Bushveld Igneous Compl. and other layer. Intr., 1: 380-390.

UHLEIN, A. (1982) Geologia e mineralizações de cromita e itabiritos na Região do Serro, Minas Gerais. Diss. de Mestrado, UnB, Brasília: 189 p.

UHLEIN, A. \& DARDENNE, M.A. (1984) Estratigrafia e tectônica da Região do Serro, Borda Leste do Espinhaço Meridional. Congr. Bras. Geol., 33º, Anais, Rio de Janeiro, 5: 2282-2301.

UHLEIN, A.; ASSIS, L.C. de \& DARDENNE, M.A. (1983) As mineralizações de ouro e cromita da Sequência Vulcano Sedimentar do Serro, MG. Simp. Geol. Minas Gerais, $2^{\circ}$, Anais, Belo Horizonte : 305-320.

UHLEIN, A.; DOSSIN, I.A. \& CHAVES, M.L.S.C. (1986) Contribuição à geologia estrutural e tectônica das rochas arqueanas e proterozóicas da Serra do Espinhaço Meridional. Cong. Bras. Geol., 34º, Anais, Goiânia, 5: 2282-2301.

WYLIE, A.G.; CANDELA, P.A. \& BURKE, T.M. (1987) Compositional in usual $\mathrm{Zn}$-rich chromite from the Sykesville district of Maryland and its bearing on the origin of "ferritchromit". Am. Miner., 72: 413-422.

YANG, X.Z.; MATSUEDA, H. \& ISHIHARA, S. (1994) Mode of occurence, chemical composition, and origin of $\mathrm{Cr}$-Fe-Ti oxides of the Jinchuan Ni-Cu-PGE Deposit, China. Int. Geol. Rev., 36: 311-327.

ZAPPAROLI, A. de C.; ANGELI, N. \& HORN, A.H. (1995) Petrografia do depósito de cromita do Morro do Cruzeiro, Serro, Minas Gerais. Simp. Geol. Minas Gerais, $8^{\circ}$, Anais, Diamantina, Bol. 13 : 141-142. 